\title{
In Quest of "Stereoselective Switch" for On-Water Hydrothiolation of Terminal Alkynes Using Different Additives and Green Synthesis of Vicinal Dithioethers
}

\author{
Basudeb Basu, Kinkar Biswas, Samir Kundu, and Debasish Sengupta \\ Department of Chemistry, North Bengal University, Darjeeling 734 013, India \\ Correspondence should be addressed to Basudeb Basu; basu_nbu@hotmail.com
}

Received 30 October 2013; Accepted 18 December 2013; Published 13 February 2014

Academic Editor: Ralph Nicholas Salvatore

Copyright (c) 2014 Basudeb Basu et al. This is an open access article distributed under the Creative Commons Attribution License, which permits unrestricted use, distribution, and reproduction in any medium, provided the original work is properly cited.

On-water hydrothiolation reaction between terminal alkyne and thiol has been probed in the presence of various additives. Aromatic alkynes yield corresponding 1-alkenyl sulfides, whereas aliphatic alkynes undergo double-addition yielding vicinal disulfides in good to excellent yields. Formation of 1-alkenyl sulfides proceeds with a high degree of regioselectivity (via antiMarkovnikov addition), and switching the stereoselectivity between $E / Z$ isomers has been noticeably realized in the presence of different additives/promoters.

\section{Introduction}

Organosulfur compounds play a key role in biological processes, new materials, and chemical synthesis $[1,2]$. 1Alkenyl sulfides are important synthetic intermediates in total synthesis of many naturally occurring and biologically active compounds as well as versatile building blocks for many functionalized molecules [3-9]. The synthetic utility of alkenyl sulfides has been demonstrated in several reports by different research groups [10-17]. Increasing demand for alkenyl sulfides in material science, organic, and bioorganic chemistry has furthered the development of new synthetic methods [6,18-21]. The addition of thiols to alkynes is considered as one of the straightforward methods to obtain vinyl sulphides either catalyzed by transition metal complexes [22-39], or base-promoted [40-44] and/or through free radicals [21, 45-48]. This reaction is often judged as a part of "click chemistry" and a process of high atom economy [ 49 , 50]. Mechanistically, addition of thiols to alkynes is believed to occur (i) via radical pathway producing unselective mixture of (E/Z)-anti-Markovnikov vinyl sulphides, (ii) basemediated nucleophilic addition giving all types of adducts, or (iii) transition-metal complex catalyzed processes yielding Markovnikov vinyl sulphides and $(E)$ anti-Markovnikov vinyl sulphides (Scheme 1). Varying degrees of stereo- and regioselectivity and turnover are reported in the literature [22-48].

Additives are a kind of reagents whose effects are very much similar to catalysts. They have often shown a profound role in variety of organic reactions in terms of the rate of the reaction, yield of the product, or change in the course of the reaction $[51,52]$. In hydrothiolation, most reports in the literature described the formation of thermodynamically more stable $E$-vinyl sulfide in considerable excess over the $Z$-isomer. On the other hand, hydrothiolation, particularly of aryl and benzyl thiols and catalyzed by transition-metal complexes, often produces a mixture of anti-Markovnikov $E$ alkenyl sulfide (syn addition) and Markovnikov adduct and thus suffers from poor regioselectivity. Among the transition metal catalysts, rhodium complexes, both in homogeneous and heterogeneous forms, have exhibited high catalytic activity [51, 52]. Recently, $\operatorname{In}(\mathrm{OTf})_{3}$ has been shown to selectively catalyze both Markovnikov and anti-Markovnikov hydrothiolation of terminal alkynes [38]. However, transition metal complexes are generally expensive, their uses are not ecofriendly, and the course of the reaction might suffer deactivation due to the formation of strong metalsulphur bonds [53]. More regioselective (anti-Markovnikov) on-water hydrothiolation processes have been reported in 


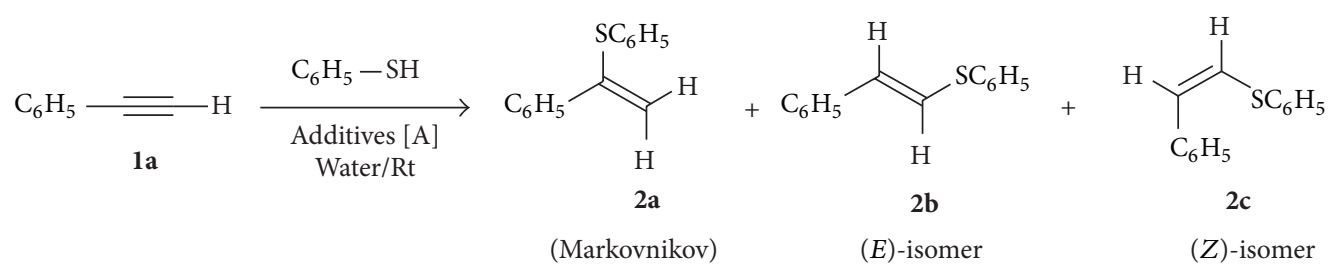

(Anti-Markovnikov)

SCHEME 1: 1-Alkenyl sulphides from hydrothiolation of terminal alkynes.

the absence $[45-48,54]$ or presence of some additives like $\beta$-cyclodextrine [55]. Indeed, there are large varieties of reagents/catalysts that are used in the hydrothiolation of terminal alkynes with varying degrees of success in controlling stereo- and regioselectivity. However, many reports include expensive metal catalysts, nonaqueous solvents, and high temperature and moreover lack (E/Z)-stereoselectivity. In practice, there is no general guideline by which one can proceed to prepare a specific stereoisomer of a vinylic sulfide using this straightforward and atom-economic reaction under mild and environment-friendly conditions. Moreover, there are conditions that give rise to selective formation of the thermodynamically favoured (E)-alkenyl sulfide, it remains an unmet and elusive goal to develop optimum conditions that selectively produce $(Z)$-alkenyl sulfides under complete metal-free, base-free and on-water conditions. Since hydrothiolation of alkynes is a robust, atom-economic and highly useful synthetic method in $\mathrm{C}-\mathrm{S}$ bond formation [6], we undertook a systematic investigation on the stereoand regioselective addition of aliphatic and aromatic thiols to terminal alkynes in the presence of different additives in catalytic quantities under on-water conditions. We report herein our studies that constitute a rather broad guideline of "stereoselective switch" for the preparation of stereoselective (E/Z)-1-alkenyl sulfides.

\section{Materials and Methods}

All compounds were identified by ${ }^{1} \mathrm{H}$ - and ${ }^{13} \mathrm{C}$-NMR spectra, recorded on a Bruker AV300 spectrometer operating at 300 and $75 \mathrm{MHz}$, respectively, and supported by FT-IR spectra. All NMR spectra were measured in chloroform-d. Chemical shifts are given in $\delta(\mathrm{ppm})$ downfield from TMS. Analytical thin-layer chromatography (tlc) was performed on precoated aluminum plates from Merck silica gel $60 \mathrm{~F}_{254}$ as the adsorbent (layer thickness $0.25 \mathrm{~mm}$ ). The developed plates were air-dried and exposed to UV light. Column chromatography was performed on silica gel (source: SRL India; 60-120 mesh).

2.1. General Procedure for Monohydrothiolation of Alkynes. To a mixture of alkyne $(1 \mathrm{mmol})$, thiol $(1.1 \mathrm{mmol})$ in water $(0.5 \mathrm{~mL})$ was added to the additive $(1 \mathrm{mmol})$ and stirred at room temperature $\left(25-30^{\circ} \mathrm{C}\right)$ for $2-5 \mathrm{~h}$ (TLC). The reaction mixture was extracted with diethyl ether $(3 \times 10 \mathrm{~mL})$, and the combined organic layer was washed with brine and then dried over $\mathrm{Na}_{2} \mathrm{SO}_{4}$. Evaporation of solvent under vacuo afforded an oily residue, which was passed through a short bed of silica gel, and NMR spectrum was recorded to evaluate the percent of $(E / Z)$ isomers. NMR spectral data and scanned copies of selected NMR spectra are given in the Supplementary Material available online at http://dx.doi.org/10.1155/2014/358932 and are found to be in good agreement with those reported.

2.2. General Procedure for Dihydrothiolation of Alkynes. In a mixture of alkyne $(1 \mathrm{mmol})$, thiol $(2.2 \mathrm{mmol})$ in water $(0.5 \mathrm{~mL})$ was stirred for 5-9 h at room temperature (TLC). The reaction mixture was then extracted with diethyl ether (3 $\times 10 \mathrm{~mL}$ ), and the combined organic layer was washed with brine and then dried over $\mathrm{Na}_{2} \mathrm{SO}_{4}$. Evaporation of solvent under vacuo afforded an oily residue, which was passed through a short bed of silica gel to afford 1, 2-disulfides in good to excellent yields. The products were identified on the basis of ${ }^{1} \mathrm{H},{ }^{13} \mathrm{C}$ NMR spectral data, and/or by comparison with the data reported in the literature. NMR spectral data and scanned copies of selected NMR spectra $\left({ }^{1} \mathrm{H}\right.$ - and $\left.{ }^{13} \mathrm{C}\right)$ are given in the Supplementary Material.

\section{Results and Discussion}

Preliminary studies on the influence of catalyst and/or promoter on hydrothiolation were studied with a model reaction of phenyl acetylene (1a) and benzenethiol in the presence of various homogeneous and heterogeneous additives/promoters under on-water conditions at room temperature. Screening of additives/promoters included inorganic salts, water-soluble organic molecules, amino acids, surfactants, or heterogeneous ion-exchange resins, and the results are summarized in Table 1 . Since the hydrothiolated adducts are formed in varying ratios ( $E / Z$ ratios), the results in Table 1 have been arranged showing a gradual change in the formation of $(E)$-vinyl sulfide (2b) to the $(Z)$-isomer (2c). The screening shows that the $E / Z$ ratio in favor of $(E)$-vinyl sulfide $(87: 13)$ is formed in the presence of $\mathrm{NaCl}$ (Table 1 , entry 3 ), while the major $(Z)$-vinyl sulfide is obtained in the presence of a combination of amberlite resins $(\mathrm{Cl})$ and $\mathrm{FeCl}_{3} \cdot 6 \mathrm{H}_{2} \mathrm{O}$ (entry $23 ; E / Z$ ratio $22: 78$ ). The stereochemical outcome favouring the $(E)$-isomer is also seen when the reaction is carried out at higher temperature $\left(65^{\circ} \mathrm{C}\right)$ and continued for longer reaction time $(10 \mathrm{~h})$ (entry 11; $E / Z$ ratio $88: 12$ ). However, a specific observation may be noted from this study that the on-water additions do not give rise to the formation of any Markovnikov adduct; that is, in no case was the other regioisomer (2a) obtained. The NMR spectral data 
TABLE 1: Role of additives in the addition of PhSH to phenylacetylene under on-water conditions at room temperature producing selectively anti-Markovnikov adducts ${ }^{\mathrm{a}}$.

\begin{tabular}{|c|c|c|c|c|c|}
\hline & & $\frac{\mathrm{C}}{\mathrm{Ad}}$ & & $\overbrace{\mathrm{H}}^{\mathrm{SC}_{6} \mathrm{H}_{5}}+\underbrace{\mathrm{C}_{6} \mathrm{H}_{5}}_{\mathrm{H}} \mathrm{SC}_{6} \mathrm{H}_{5}$ & \\
\hline Entry & Additive $[\mathrm{A}]^{\mathrm{b}}$ & $(E / Z) \mathrm{ratio}^{\mathrm{c}, \mathrm{d}}$ & Entry & Additive $[\mathrm{A}]^{\mathrm{b}}$ & $(E / Z)$ ratio $^{c, d}$ \\
\hline 1 & Nil (neat) & $83: 17$ & 13 & CuI-Catechol violet & $60: 40$ \\
\hline 2 & Nil (water) & $80: 20$ & 14 & Amberlite resins $(\mathrm{Cl})$ & $58: 42$ \\
\hline 3 & $\mathrm{NaCl}$ & $87: 13$ & 15 & $\mathrm{n}-\mathrm{Bu}_{4} \mathrm{NBr}$ & $57: 43$ \\
\hline 4 & Sucrose & $85: 15$ & 16 & D-Glucose & $56: 44$ \\
\hline 5 & $\mathrm{CF}_{3} \mathrm{COOH}$ & $78: 22$ & 17 & $\mathrm{CuI}$ & $52: 48$ \\
\hline 6 & $\mathrm{BF}_{3} \cdot \mathrm{Et}_{2} \mathrm{O}$ & $76: 24$ & 18 & Cholesterol & $51: 49$ \\
\hline 7 & Catechol violet & $75: 25$ & 19 & СТАВ & $49: 51$ \\
\hline 8 & L-Proline & $70: 30$ & 20 & $\mathrm{FeCl}_{3} \cdot 6 \mathrm{H}_{2} \mathrm{O}$ & $44: 56$ \\
\hline 9 & Glycin & $69: 31$ & 21 & Amberlyst resins $(\mathrm{OH})$ & $40: 60$ \\
\hline 10 & Starch & $64: 36$ & 22 & D-Glucose and $\mathrm{FeCl}_{3} \cdot 6 \mathrm{H}_{2} \mathrm{O}$ & $35: 65$ \\
\hline $11^{\mathrm{e}}$ & Water $\left(65^{\circ} \mathrm{C}\right)$ & $88: 12$ & 23 & Amberlite resins $(\mathrm{Cl})$ and $\mathrm{FeCl}_{3} \cdot 6 \mathrm{H}_{2} \mathrm{O}$ & $22: 78$ \\
\hline 12 & Water $\left(65^{\circ} \mathrm{C}\right)$ & $64: 36$ & & 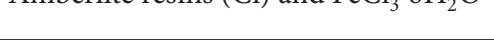 & \\
\hline
\end{tabular}

${ }^{\mathrm{a}}$ Reaction conditions: phenyl acetylene $(0.5 \mathrm{mmol}), \mathrm{PhSH}(0.55 \mathrm{mmol})$, water $(1 \mathrm{~mL}), 2 \mathrm{~h} .{ }^{\mathrm{b}}$ Additive $[\mathrm{A}](2 \mathrm{~mol} \%) .{ }^{\mathrm{c}} \mathrm{E} / \mathrm{Z}$ ratio was determined by ${ }^{\mathrm{l}} \mathrm{H} \mathrm{NMR}$ of the crude mixture. ${ }^{\mathrm{d}}$ Yield of the mixture of stereoisomers after chromatographic purification varies in the range $80-90 \% .{ }^{\mathrm{e}}$ The reaction was continued for $10 \mathrm{~h}$; all other reactions were carried out at room temperature unless otherwise mentioned.

of the unpurified products indicated only a mixture of $\mathbf{2 b}$ and $2 \mathbf{c}$, and indeed there was no trace of $\mathbf{2 a}$.

At this point, effect of functional groups in the aromatic moiety in either of the addition partners could be worth investigating. Since a combination of ion-exchange resins and ferric chloride showed a better selectivity towards the formation of $(Z)$-vinyl sulfide, this study was performed under similar conditions. The results are presented in Table 2. It is seen that both electron-donating and electronwithdrawing functional groups present on the aryl ring can give rise to the anti-Markovnikov hydrothiolation products in excellent yields (85-94\%). The highest $(Z)$-selectivity was found in the reaction between phenyl acetylene and $p$ methoxybenzenethiol (Table 2, entry 4; E/Z $12: 88$ ), possibly due to the easy emulsification of the alkyne in water upon stirring, which might be supportive, in addition to the presence of the additive. On the other hand, presence of the electron-withdrawing group (fluorine) on the thiol part did not show any appreciable influence towards stereoselective addition yielding the $(E)$-isomer in major quantity (entries 6-7). It seems that there is not much electronic influence of the functional groups in the aryl ring of either of the addition partners; rather their stability in water in the presence of the additive might have some control towards anti-Markovnikov stereoselectivity.

Further studies of aryl acetylenes (terminal) with aliphatic thiols in the presence of one equivalent of D (+)glucose showed a general trend in favour of the formation of ( $Z$ )-vinyl sulphides. For example, phenyl acetylene or $p$-tolyl acetylene undergoes hydrothiolation in the presence of $n$-alkyl thiols that afforded the corresponding 1-alkenyl sulphides with $(E / Z)$ ratios $(14: 86)$. The results are summarized in Table 3.
Since there is significant reactivity difference between aliphatic and aromatic thiols [56,57], we ought to investigate the stereochemical outcome in two other cases: hydrothiolation of (i) aliphatic terminal alkynes and aliphatic thiols and (ii) aliphatic terminal alkynes and aromatic thiols. It has been seen from previous reports that aliphatic alkynes undergo dihydrothiolation yielding vicinal disulfides only irrespective of the nature of the thiol $[45,54]$. Thus, aliphatic terminal alkynes were subjected to hydrothiolation with aromatic and aliphatic thiols under on-water conditions. Seemingly, there was an influence of additives on this double-addition reaction. The results are presented in Table 4, which show that aliphatic terminal alkynes undergo double- additions yielding finally 1, 2-disulfides only in the presence or absence of D (+)-glucose.

With regard to the mechanism of hydrothiolation of terminal alkynes in water, the literature reports are of different views. For example, Bhadra and Ranu [54], in their studies on water-promoted regioselective hydrothiolation, ruled out the likeliness of a radical pathway as the reaction proceeds in the presence of dissolved oxygen. On the other hand, Jin et al. [45], hinted that the reaction probably proceeds through a radical mechanism under similar conditions. The latter group further observed that the reaction does not occur in the presence of galvinoxyl-free radical, although use of such radical quencher does not always prove radical mechanism $[54,55]$. Our studies indeed demonstrated a role of additives in governing the stereoselectivity but the specific function of the additive, particularly in aqueous medium, and the mechanistic routes are not clear at this time. Furthermore, carrying out the reaction in the presence of radical initiator (AIBN) or light did not make the process faster appreciably. Several transition metal complexes are 
TABLE 2: Hydrothiolation of aryl thiol [B] to aryl acetylene $[\mathrm{A}]$ in $(1.1: 1)$ in water at room temperature.

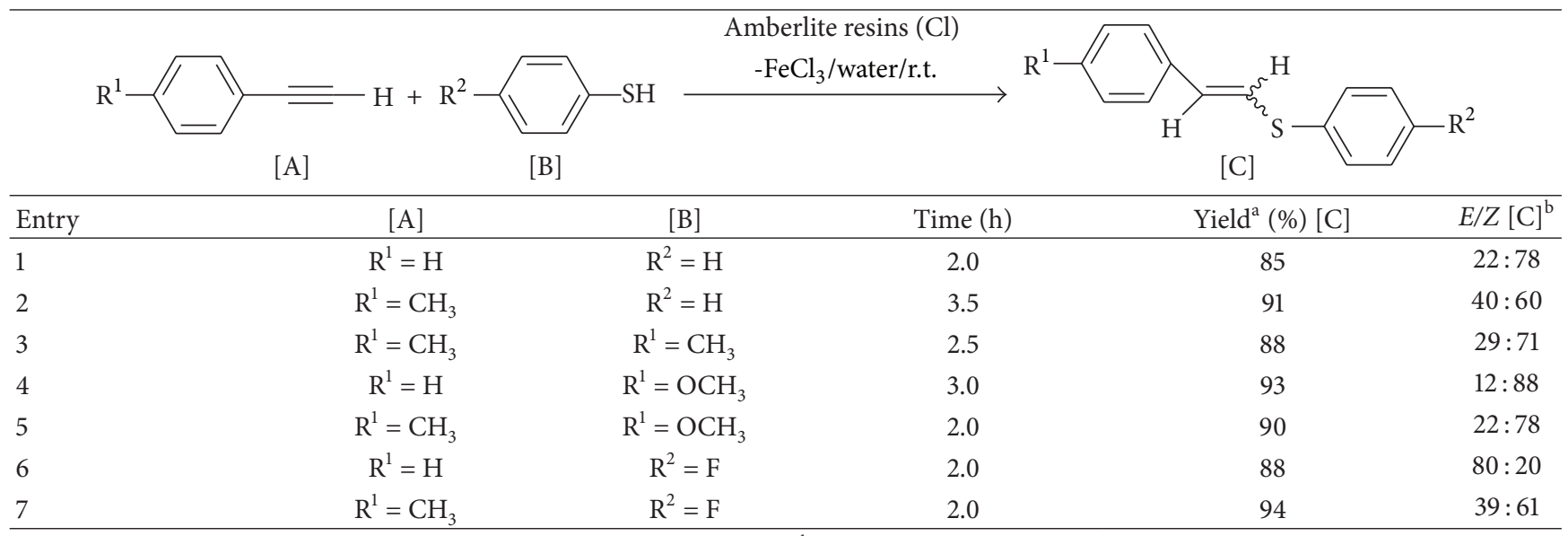

${ }^{\mathrm{a}}$ Yield represents the product $[\mathrm{C}]$ after purification by column chromatography. ${ }^{\mathrm{b}} \mathrm{E} / \mathrm{Z}$ ratio was determined by ${ }^{1} \mathrm{H}$ NMR of the crude mixture.

TABLE 3: Hydrothiolation aromatic terminal alkynes with aliphatic thiols.

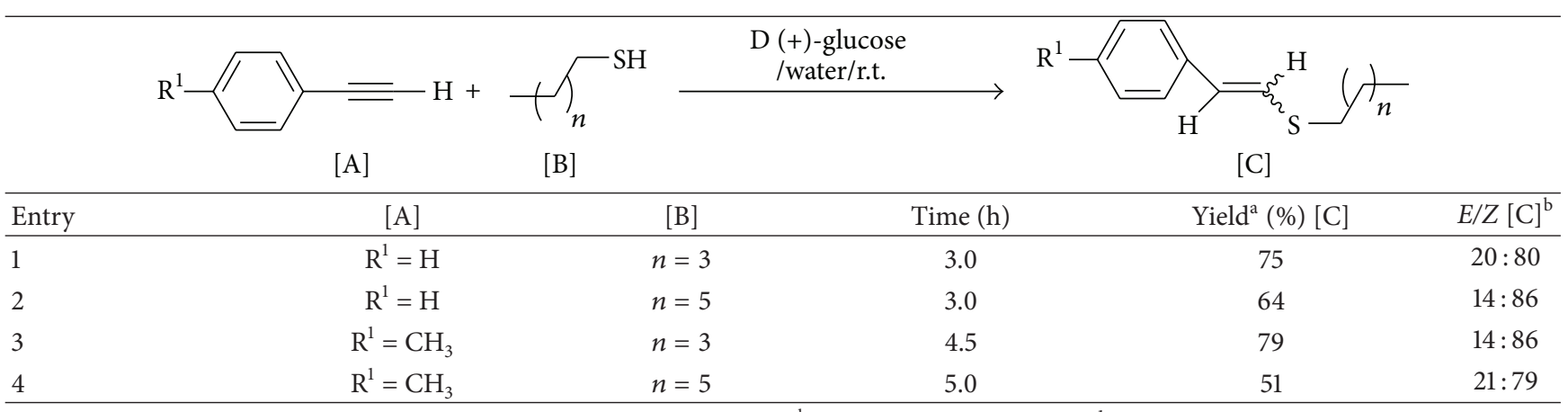

${ }^{\mathrm{a}}$ Yield represents the product $[\mathrm{C}]$ after purification by column chromatography. ${ }^{\mathrm{b}} \mathrm{E} / \mathrm{Z}$ ratio was determined by ${ }^{1} \mathrm{H}$ NMR of the crude product mixture.

TABLE 4: Dihydrothiolation of aliphatic alkyne with thiols in water at room temperature.

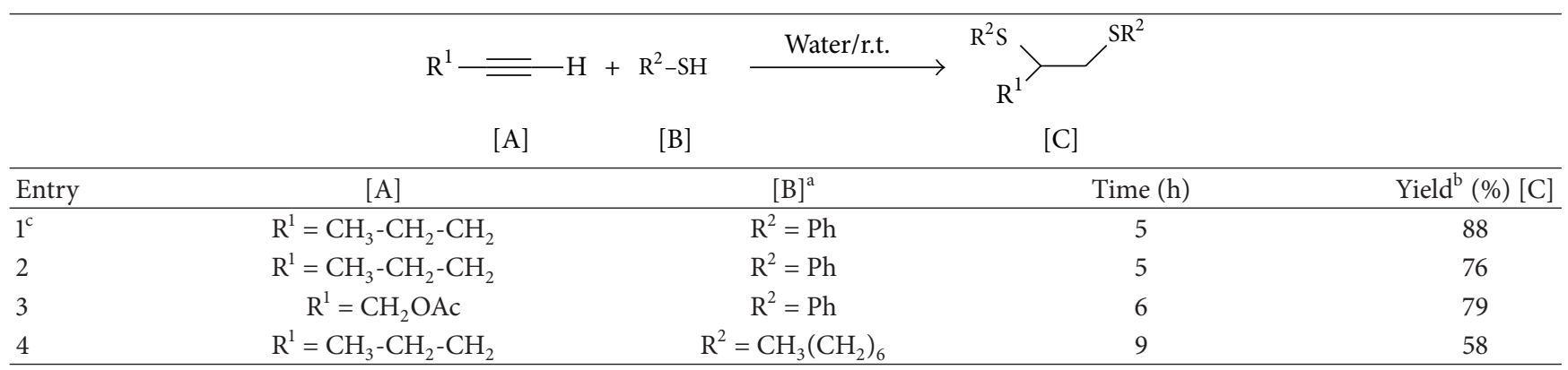

${ }^{\mathrm{a}}[\mathrm{A}]:[\mathrm{B}]$ is $1: 2.2 .{ }^{\mathrm{b}}$ Yield represents the product $[\mathrm{C}]$ after purification by column chromatography. ${ }^{\mathrm{c}} \mathrm{D}(+)$-Glucose (1 equiv) was added.

known to catalyze the process of hydrothiolation via radical intermediates leading to major anti-Markovnikov 1-alkenyl sulfides. In the absence of such metal complexes, it seems that stabilization of the reactive species by water as well as by the additive might govern the course of the reaction as well as the stereoselectivity.

\section{Conclusions}

In quest of finding "stereoselective switch" for the hydrothiolation of terminal alkynes under on-water conditions, our studies apparently revealed two types of additives that could lead to the stereoselective formation of the (Z)-1-alkenyl sulfides in substantial quantities depending on the nature of both reacting partners. Since most of the metal-free methods describe formation of the (E)-1-alkenyl sulfides in major amount, the present findings could steer in designing mild and green reaction conditions for stereoselective preparation of $(E / Z)$ alkenyl sulphides under on-water conditions.

\section{Conflict of Interests}

The authors declare that there is no conflict of interests regarding the publication of this paper. 


\section{Acknowledgments}

The authors are grateful to the Department of Science and Technology, New Delhi, for financial support (Grant no. SR/S1/OC-86/2010 (G)). Samir Kundu and Debasish Sengupta respectively thank the UGC and CSIR, New Delhi, for awarding research fellowships.

\section{References}

[1] R. J. W. Cremlyn, An Introduction to Organosulfur Chemistry, Wiley, New York, NY, USA, 1996.

[2] G. H. Whitham, Organosulfur Chemistry, Oxford University Press, New York, NY, USA, 1995.

[3] M. D. McReynolds, J. M. Dougherty, and P. R. Hanson, "Synthesis of phosphorus and sulfur heterocycles via ring-closing olefin metathesis," Chemical Reviews, vol. 104, no. 5, pp. 2239-2258, 2004.

[4] N. V. Zyk, E. K. Beloglazkina, M. A. Belova, and N. S. Dubinina, "Methods for the synthesis of vinyl sulfides," Russian Chemical Reviews, vol. 72, no. 9, pp. 769-786, 2003.

[5] I. P. Beletskaya and V. P. Ananikov, "Unusual influence of the structures of transition metal complexes on catalytic C-S and C-Se bond formation under homogeneous and heterogeneous conditions," European Journal of Organic Chemistry, vol. 2007, no. 21, pp. 3431-3444, 2007.

[6] T. Kondo and T. A. Mitsudo, "Metal-catalyzed carbon-sulfur bond formation," Chemical Reviews, vol. 100, no. 8, pp. 32053220, 2000.

[7] A. Y. Sizov, A. N. Kovregin, and A. F. Ermolov, "Fluorinecontaining alkyl(aryl) vinyl sulfides," Russian Chemical Reviews, vol. 72, no. 4, pp. 357-374, 2003.

[8] F. Bernardi, I. G. Csizmadia, and A. Mangini, Studies in Organic Chemistry, Vol. 19, Organic Sulfur Chemistry, Theoretical and Experimental Advances, Elsevier, Amsterdam, The Netherlands, 1985.

[9] E. Block, Reactions of Organosulfur Compounds, Academic Press, New York, NY, USA, 1978.

[10] J. C. Kloxin, F. T. Scott, and N. C. Bowman, "Stress relaxation via addition fragmentation chain transfer in a thiol-ene photopolymerization," Macromolecules, vol. 42, no. 7, pp. 2551-2556, 2009.

[11] D. Konkolewicz, A. Gray-Weale, and S. Perrier, "Hyperbranched polymers by thiol-yne chemistry: from small molecules to functional polymers," Journal of the American Chemical Society, vol. 131, no. 50, pp. 18075-18077, 2009.

[12] A. Cohen, A. Yeori, I. Goldberg, and M. Kol, "Group 4 complexes of a new [OSSO]-type dianionic ligand. Coordination chemistry and preliminary polymerization catalysis studies," Inorganic Chemistry, vol. 46, no. 20, pp. 8114-8116, 2007.

[13] K. Beckerle, R. Manivannan, B. Lian et al., "Stereospecific styrene enchainment at a titanium site within a helical ligand framework: evidence for the formation of homochiral polystyrene," Angewandte Chemie, vol. 46, no. 25, pp. 47904793, 2007.

[14] B. Lian, K. Beckerle, T. P. Spaniol, and J. Okuda, "Regioselective 1-hexene oligomerization using cationic bis(phenolato) group 4 metal catalysts: switch from 1,2- to 2,1-insertion," Angewandte Chemie, vol. 46, no. 44, pp. 8507-8510, 2007.

[15] A. Valdebenito and M. V. Encinas, "Thiophenols as chain transfer agents in the polymerization of vinyl monomers," Polymer, vol. 46, no. 24, pp. 10658-10662, 2005.
[16] S. Poulain, S. Julien, and E. Dunach, "Conversion of norbornene derivatives into vicinal-dithioethers via S8 activation," Tetrahedron Letters, vol. 46, no. 41, pp. 7077-7079, 2005.

[17] A. Sabarre and J. Love, "Synthesis of 1,1-disubstituted olefins via catalytic alkyne hydrothiolation/Kumada cross-coupling," Organic Letters, vol. 10, no. 18, pp. 3941-3944, 2008.

[18] P. I. Clemenson, "The chemistry and solid state properties of nickel, palladium and platinum bis(maleonitriledithiolate) compounds," Coordination Chemistry Reviews, vol. 106, pp. 171203, 1990.

[19] E. G. Hope and W. Levason, "Recent developments in the coordination chemistry of selenoether and telluroether ligands," Coordination Chemistry Reviews, vol. 122, no. 1-2, pp. 109-170, 1993.

[20] C. Lauterbach and J. Fabian, "Density functional derived structures and molecular properties of nickel dithiolenes and related complexes," European Journal of Inorganic Chemistry, vol. 1999, no. 11, pp. 1995-2004, 1999.

[21] M. E. Peach, The Chemistry of the Thiol Group Vol. 2, Wiley, London, UK, 1974.

[22] D. A. Malyshev, N. M. Scott, N. Marion et al., "Homogeneous nickel catalysts for the selective transfer of a single arylthio group in the catalytic hydrothiolation of alkynes," Organometallics, vol. 25, no. 19, pp. 4462-4470, 2006.

[23] V. P. Ananikov, D. A. Malyshev, I. P. Beletskaya, G. G. Aleksandrov, and I. L. Eremenko, "Nickel(II) chloride-catalyzed regioselective hydrothiolation of alkynes," Advanced Synthesis and Catalysis, vol. 347, no. 15, pp. 1993-2001, 2005.

[24] C. Cao, L. R. Fraser, and J. A. Love, "Rhodium-catalyzed alkyne hydrothiolation with aromatic and aliphatic thiols " Journal of the American Chemical Society, vol. 127, no. 50, pp. 17614-17615, 2005.

[25] L. R. Fraser, J. Bird, Q. Wu, C. Cao, B. O. Patrick, and J. A. Love, "Synthesis, structure, and hydrothiolation activity of rhodium pyrazolylborate complexes," Organometallics, vol. 26, no. 23, pp. 5602-5611, 2007.

[26] J. Yang, A. Sabarre, L. R. Fraser, B. O. Patrick, and J. A. Love, "Synthesis of 1,1-disubstituted alkyl vinyl sulfides via RhodiumCatalyzed alkyne hydrothiolation: scope and limitations," Journal of Organic Chemistry, vol. 74, no. 1, pp. 182-187, 2009.

[27] A. Ogawa, T. Ikeda, K. Kimura, and T. Hirao, "Highly regio- and stereocontrolled synthesis of vinyl sulfides via transition-metalcatalyzed hydrothiolation of alkynes with thiols," Journal of the American Chemical Society, vol. 121, no. 22, pp. 5108-5114, 1999.

[28] S. Shoai, P. Bichler, B. Kang, H. Buckley, and J. A. Love, "Catalytic alkyne hydrothiolation with alkanethiols using Wilkinson's catalyst," Organometallics, vol. 26, no. 24, pp. 5778-5781, 2007.

[29] Y. Yang and R. M. Rioux, "Highly regio- and stereoselective hydrothiolation of acetylenes with thiols catalyzed by a welldefined supported Rh complex," Chemical Communications, vol. 47, no. 23, pp. 6557-6559, 2011.

[30] R. Gerber and C. M. Frech, "Alkyne hydrothiolation catalyzed by a dichlorobis(aminophosphine) complex of palladium: selective formation of cis-configured vinyl thioethers," Chemistry A, vol. 18, no. 29, pp. 8901-8905, 2012.

[31] H. Kuniyasu, A. Ogawa, K. I. Sato, I. Ryu, N. Kambe, and N. Sonoda, "The first example of transition-metal-catalyzed addition of aromatic thiols to acetylenes," Journal of the American Chemical Society, vol. 114, no. 14, pp. 5902-5903, 1992. 
[32] A. Ogawa, A. Kudo, and T. Hirao, "Palladium-catalyzed hydroselenation of allenes with benzeneselenol," Tetrahedron Letters, vol. 39, no. 29, pp. 5213-5216, 1998.

[33] C. J. Weiss and T. J. Marks, "Organozirconium complexes as catalysts for Markovnikov-selective intermolecular hydrothiolation of terminal alkynes: scope and mechanism," Journal of the American Chemical Society, vol. 132, no. 30, pp. 10533-10546, 2010.

[34] A. Corma, C. Gonzalez-Aellano, M. Iglesias, and F. Sanchez, "Efficient synthesis of vinyl and alkyl sulfides via hydrothiolation of alkynes and electron-deficient olefins using soluble and heterogenized gold complexes catalysts," Applied Catalysis A, vol. 375, no. 1, pp. 49-54, 2010.

[35] L. D. Field, B. A. Messerle, K. Q. Vuong, and P. Turner, "Rhodium(I) and iridium(I) complexes containing bidentate phosphine-imidazolyl donor ligands as catalysts for the hydroamination and hydrothiolation of alkynes," Dalton Transactions, no. 18, pp. 3599-3614, 2009.

[36] X. L. Zheng, X. L. Xu, and Y. M. Zhang, "Stereoselective michael addition and michael-aldol tandem reaction of diorganyl diselenides or disulfides with conjugated alkynones mediated by samarium diiodide," Chinese Journal of Chemistry, vol. 22, no. 9, pp. 958-965, 2004.

[37] J. S. Yadav, B. V. S. Reddy, A. Raju, K. Ravindar, and G. Baishya, "Hydrothiolation of unactivated alkynes catalyzed by indium(III) bromide," Chemistry Letters, vol. 36, no. 12, pp. 1474-1475, 2007.

[38] R. Sarma, N. Rajesh, and D. Prajapati, "Indium(III) catalysed substrate selective hydrothiolation of terminal alkynes," Chemical Communications, vol. 48, no. 33, pp. 4014-4016, 2012.

[39] M. Weiwer, L. Coulombel, and E. Dunach, "Regioselective indium(III) trifluoromethanesulfonate-catalyzed hydrothiolation of non-activated olefins," Chemical Communications, no. 3 , pp. 332-334, 2006.

[40] A. Kondoh, K. Takami, H. Yorimitsu, and K. Oshima, "Stereoselective hydrothiolation of alkynes catalyzed by cesium base: facile access to (Z)-1-alkenyl sulfides," Journal of Organic Chemistry, vol. 70, no. 16, pp. 6468-6473, 2005.

[41] W. E. Truce, J. A. Simms, and M. M. Boudakian, "The stereochemistry of base-catalyzed additions of thiols to acetylenes," Journal of the American Chemical Society, vol. 78, no. 3, pp. 695696, 1956.

[42] W. E. Truce and J. A. Simms, "Stereospecific reactions of nucleophilic agents with acetylenes and vinyl-type halides. IV. The stereochemistry of nucleophilic additions of thiols to acetylenic hydrocarbons1," Journal of the American Chemical Society, vol. 78, no. 12, pp. 2756-2759, 1956.

[43] B. A. Trofimov, "Reactions of acetylene in superbasic media," Russian Chemical Reviews, vol. 50, no. 2, p. 138, 1981.

[44] W. E. Truce and G. J. W. Tichenor, "Effect of activating group on trans stereoselectivity of thiolate additions to activated acetylenes," Journal of Organic Chemistry, vol. 37, no. 15, pp. 2391-2396, 1972.

[45] Z. Jin, B. Xu, and G. B. Hammond, "Green synthesis of vicinal dithioethers and alkenyl thioethers from the reaction of alkynes and thiols in water," European Journal of Organic Chemistry, vol. 2010, no. 1, pp. 168-173, 2010.

[46] K. Griesbaum, "Problems and possibilities of the free-radical addition of thiols to unsaturated compounds," Angewandte Chemie, vol. 9, no. 4, pp. 273-287, 1970.

[47] Z.-L. Wang, R.-Y. Tang, P.-S. Luo, C.-L. Deng, P. Zhong, and J.-H. Li, "Hydrothiolation of terminal alkynes with diaryl disulfides and diphenyl diselenide: selective synthesis of (Z)-1alkenyl sulfides and selenides," Tetrahedron, vol. 64, no. 47, pp. 10670-10675, 2008.

[48] Y. Ichinose, K. Wakamatsu, K. Nozaki, J. L. Birbaum, K. Oshima, and K. Utimoto, "Et3B induced radical addition of thiols to ccetylenes," Chemistry Letters, vol. 16, no. 8, pp. 1647-1650, 1987.

[49] S. Burling, L. D. Field, B. A. Messerle, K. Q. Vuong, and P. Turner, "Rhodium(I) and iridium(I) complexes with bidentate $\mathrm{N}, \mathrm{N}$ and P,N ligands as catalysts for the hydrothiolation of alkynes," Journal of the Chemical Society. Dalton Transactions, no. 21, pp. 4181-4191, 2003.

[50] S. Ranjit, Z. Duan, P. Zhang, and X. Liu, "Synthesis of vinyl sulfides by copper-catalyzed decarboxylative C-S cross-coupling," Organic Letters, vol. 12, no. 18, pp. 4134-4136, 2010.

[51] C. J. Li, "Organic reactions in aqueous media with a focus on carbon-carbon bond formations: a decade update," Chemical Reviews, vol. 105, no. 8, pp. 3123-3166, 2005.

[52] R. Chinchilla and C. Najera, "The sonogashira reaction:a booming methodology in synthetic organic chemistry," Chemical Reviews, vol. 107, no. 3, pp. 875-922, 2007.

[53] H. Zhao, J. Peng, and M. Cai, "Heterogeneous hydrothiolation of alkynes with thiols catalyzed by diphosphino-functionalized MCM-41 anchored rhodium complex," Catalysis Letters, vol. 142, no. 1, pp. 138-142, 2012.

[54] S. Bhadra and B. C. Ranu, "Water-promoted regioselective hydrothiolation of alkynes," Canadian Journal of Chemistry, vol. 87, no. 11, pp. 1605-1609, 2009.

[55] R. Sridhar, K. Surendra, N. Srilakshmi Krishnaveni, B. Srinivas, and K. Rama Rao, "Stereoselective synthesis of E-vinyl sulfides from alkynes in water under neutral conditions using $\beta$ cyclodextrin," Synlett, no. 20, pp. 3495-3497, 2006.

[56] T. V. DeCollo and W. J. Lees, "Effects of aromatic thiols on thiol-disulfide interchange reactions that occur during protein folding," Journal of Organic Chemistry, vol. 66, no. 12, pp. 42444249, 2001.

[57] U. Burner, W. Jantschko, and C. Obinger, "Kinetics of oxidation of aliphatic and aromatic thiols by myeloperoxidase compounds I and II," FEBS Letters, vol. 443, no. 3, pp. 290-296, 1999. 

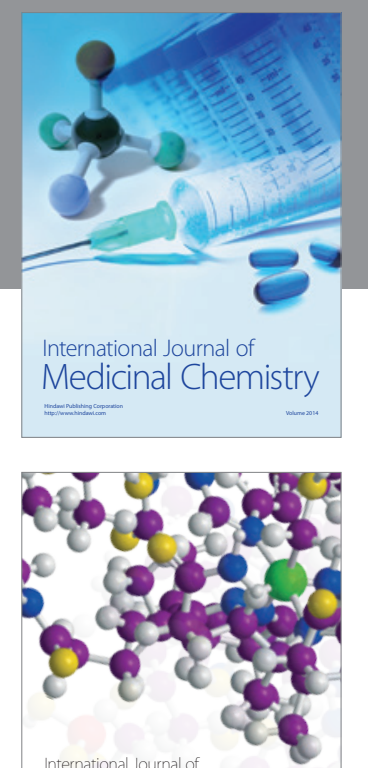

\section{Carbohydrate} Chemistry

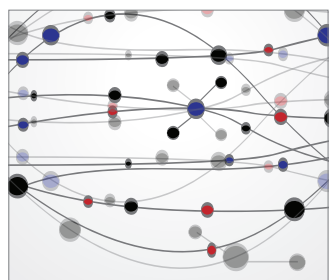

The Scientific World Journal
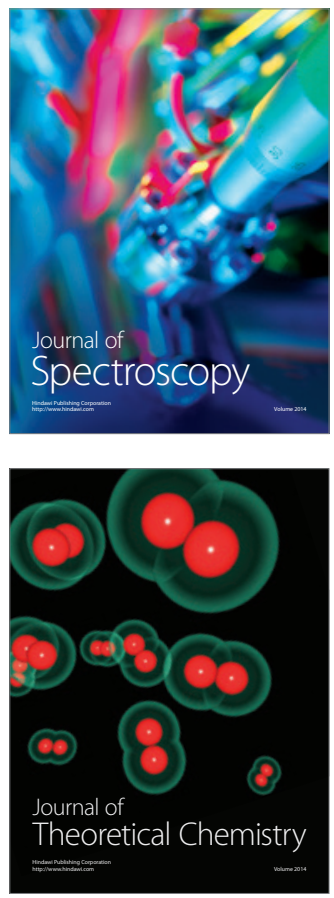
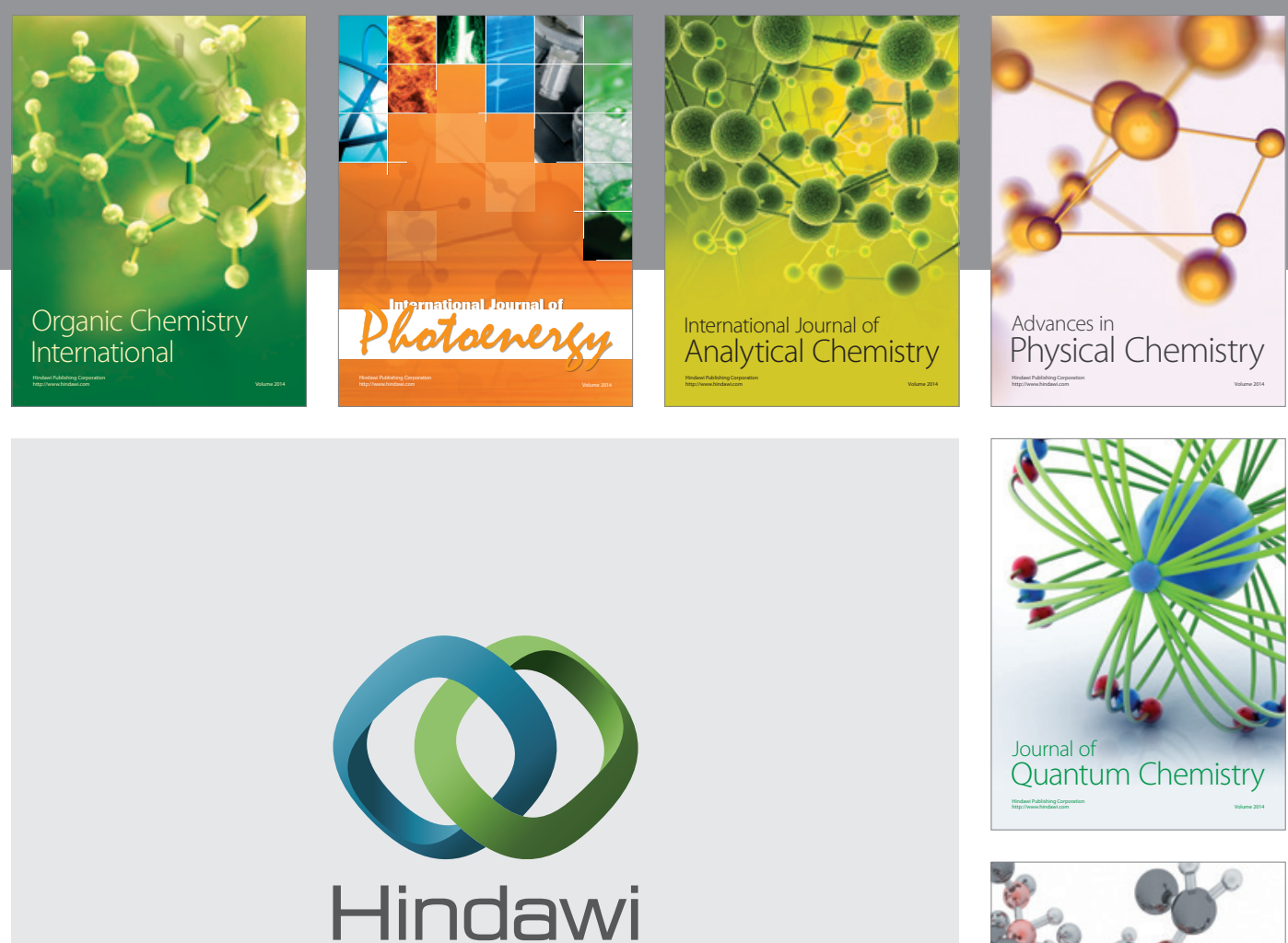

Submit your manuscripts at

http://www.hindawi.com

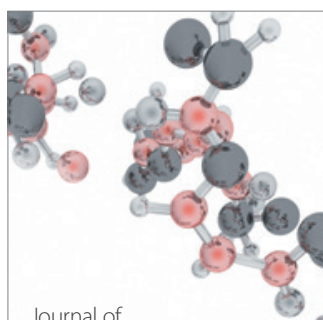

Analytical Methods

in Chemistry

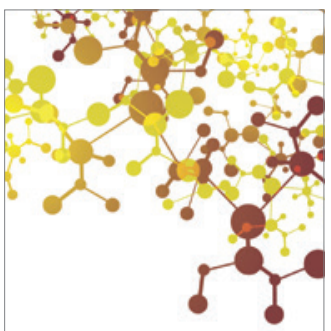

Journal of

Applied Chemistry

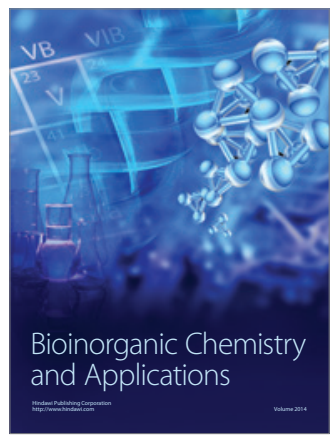

Inorganic Chemistry
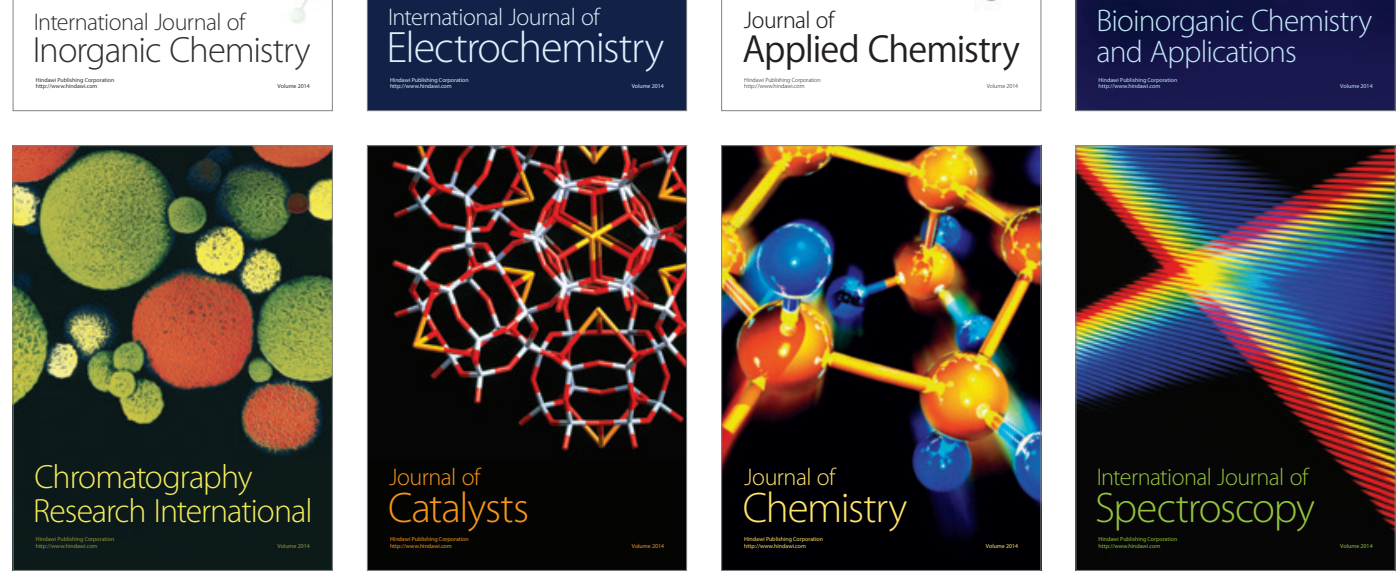